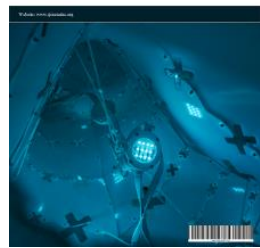

\title{
Synthesis of Water-Repellent Coating for Polyester Fabric
}

\author{
Nur Nabilah Mohd Za’im ${ }^{1}$, Hartina Mohd Yusop ${ }^{1}$, Wan Norfazilah Wan Ismail ${ }^{1 *}$ \\ ${ }^{I}$ Faculty of Industrial Sciences and Technology, Universiti Malaysia Pahang, Lebuhraya Tun Razak 26300 Kuantan, Pahang, Malaysia
}

\begin{abstract}
A new hydrophobic hexyltrimethoxysilane (HTMS) coating for polyester fabric was successfully synthesized via a one-step water-based sol-gel method under acidic condition. Five different molar ratios of HTMS: water (1;40,1:30, 1:20, 1:12 and 1:3) were prepared and the solution was deposited onto the polyester fabric by a simple dip-pad-cure process. The effect of water content on hydrophobicity was evaluated by manual testing on the treated polyester fabric samples. The effectiveness of hydrophobicity properties was further characterized using water contact angle (WCA) measurement. The optimized molar ratio of 1:3 was found to obtain the best hydrophobic property of $136.2^{\circ}$ with particle size $115.3 \mu \mathrm{m}$ measured using Particle Size Analyzer (PSA). Fourier transform infrared spectroscopy (FTIR) analysis confirmed the success of sol gel process with the presence of Si-O-Si band, which was also determined using energy dispersive X-ray spectroscopy (EDX). The Scanning Electron Microscopy (SEM) images revealed a good surface morphology of the homogenous thin xerogel coating with no visible cracks. Using HTMS without combinations of other precursors resulted in rough surface structure due to the low surface energy caused by long-chain alkyl silane in the HTMS coating and this provided the treated polyester fabric with good hydrophobicity.
\end{abstract}

\section{Keywords:}

Hydrophobic;

Water-based sol-gel;

Water Content;

Hexyltrimethoxysilane;

\section{Article History:}

$\begin{array}{llll}\text { Received: } & 27 & \text { April } & 2021 \\ \text { Revised: } & 31 & \text { July } & 2021 \\ \text { Accepted: } & 29 & \text { August } & 2021 \\ \text { Published: } & 01 & \text { October } & 2021\end{array}$

\section{1- Introduction}

Water-repellent coating helps to repel water by infusing the characteristic of "lotus effect" on the surface of material. "Lotus effect" which refers to ability of lotus leaves to make water droplet rebound and easily fall off and at the same time keeping it clean, has received a lot of attention from researchers. The effect has been studied in the context of application using modern technologies [1-3]. Numerous studies have focused on creating a surface that can resist the absorption of water either by modifying a lower surface energy substance on the rough surface or by increasing the surface roughness of the lower surface energy substance [4-5]. Many governmental and private laboratories are currently in the process of improving the function of hydrophobic coating by varying the synthetic route in the production process [6]. Despite the rapid development in coating technologies, the ultimate aim of research is to simplify the process and in an easily controlled environment, and eventually make it more economical. Sol-gel technique met all these requirements. It is efficient, easy to perform, and it can be operated at low temperature with no requirement of complicated conditions [7-9]. Additionally, sol-gel technique only involves a series of simple hydrolysis and condensation reactions, which starts from using an alkoxysilane in alcohol and other polar solvents [10]. Therefore, the sol-gel technique was selected for this study.

Sol-gel synthesis offers the use of wide range of raw materials. Nano-sized silica is one of the most common oxide nanoparticles. The combination of silica has been extensively used for preparation of hydrophobic characteristic of the substrate. Preliminary experiments used polydimethylsiloxane (PDMS) and silica $\left(\mathrm{SiO}_{2}\right)$ nanoparticles for coating on

* CONTACT: norfazilah@ump.edu.my

DOI: http://dx.doi.org/10.28991/esj-2021-01309

(C) 2021 by the authors. Licensee ESJ, Italy. This is an open access article under the terms and conditions of the Creative Commons Attribution (CC-BY) license (https://creativecommons.org/licenses/by/4.0/). 
glass, paper and plastic and they showed a superhydrophobicity with WCA of $156.4^{\circ}$ [11]. Nabipour et al. synthesized ammonium hexametaphosphate (NH4-HMP), laponite (LAP), and hexadecyltrimethoxysilane (HDTMS) using sol gel method to enhance the hydrophobicity (WCA of $138^{\circ}$ ) and flame retardancy of the cotton fabric [12]. The superhydrophobic surface of cotton was fabricated using silica nanoparticles, zinc oxide $(\mathrm{ZnO})$ nano-rods and decyltrimethoxysilane (DTMS) [13]. Although the combination of precursor could give the hydrophobicity characteristic, some of the chemicals are expensive and potentially harmful during the preparation process. Thus, HTMS was used as it is inexpensive, less toxic and its chemical composition can be easily adjusted to show hydrophobicity.

The nature of solvent is also crucial to determine the dispersion of hydrophobic particles and the usage of alcohol as the solvent has been proven to give a brilliant result [14-15]. Today's research organizations are becoming more environmentally conscious and aiming to move toward more sustainable practices. As a result, water-based dispersions have become popular as it poses less environmental damage. Hence, deionized water $\left(\mathrm{H}_{2} \mathrm{O}\right)$ was chosen as the solvent for the preparation of silica hydrosol. Consequently, in order to overcome the immiscibility of the alkoxide system in aqueous media, alcohol was employed as co-solvent but its amount was greatly reduced. In this study, we present a simple, fast, low cost and environmentally friendly water-based sol-gel process to prepare hydrophobic coating by using HTMS in the presence of the acid catalyst. Coating was then deposited onto the polyester fabric sample using dip-padcure technique. HTMS was used as precursor in this research due to its good adhesion to the substrate which may increase the water contact angle [16]. Additionally, it serves as a cross linker resulting in dense and less hydrophilic of the substrate [17]. Thus means it can increase the hydrophobicity of the substrate. The prepared hydrophobic fabric has preserved its softness and smoothness providing comfort to the wearer.

\section{2- Research Methodology}

\section{2-1- Materials and Reagents}

The precursor HTMS together with analytical grade of absolute ethanol (EtOH) and sulfuric acid $\left(\mathrm{H}_{2} \mathrm{SO}_{4}\right)$ used as cosolvent and catalyst respectively were purchased from Sigma Aldrich (Missouri, USA). Deionized water used as solvent was obtained from a Milli-Q water purification system (Millipore) in the laboratory. Commercial polyester fabric was used as the substrates and purchased from the local market.

\section{2-2- Preparation of Silica Hydrosol and Treatment of Fabric}

Five different molar ratios of HTMS: $\mathrm{H}_{2} \mathrm{O}(1: 3,1: 12 ; 1: 20 ; 1: 30,1: 40)$ were prepared via sol-gel process in an acidic medium. For preparation of 1:3 molar composition of HTMS to water, initially a mixture of $2162 \mu \mathrm{L}$ water, $934 \mu \mathrm{L}$ ethanol and $2132 \mu \mathrm{L}$ sulfuric acid was prepared. Later, $8972 \mu \mathrm{L}$ HTMS was added into the mixture and the solution was covered using an aluminium foil to prevent evaporation. The mixture was stirred vigorously on a magnetic stirrer at 30 ${ }^{\circ} \mathrm{C}$ until a clear solution was obtained. The same steps were repeated for preparation of different molar ratios of HTMS: $\mathrm{H}_{2} \mathrm{O}(1: 12 ; 1: 20 ; 1: 30,1: 40)$ by varying the volume of water.

The $\mathrm{SiO}_{2}$ hydrosol was coated using dip-pad-cure process onto the $3 \times 3 \mathrm{~cm}$ polyester fabric sample. The fabric was dipped in the coating solution for $10 \mathrm{~min}$, and then padded using an automatic laboratory padder (TD110, TESTEX) with a nip pressure of $2 \mathrm{~kg} / \mathrm{cm}^{2}$. The coated fabrics were then dried at $80{ }^{\circ} \mathrm{C}$ for $15 \mathrm{~min}$ and cured at $120{ }^{\circ} \mathrm{C}$ for $2 \mathrm{~min}$ in an oven. Figure 1 shows the synthesizing of HTMS sols and fabric treatment process.

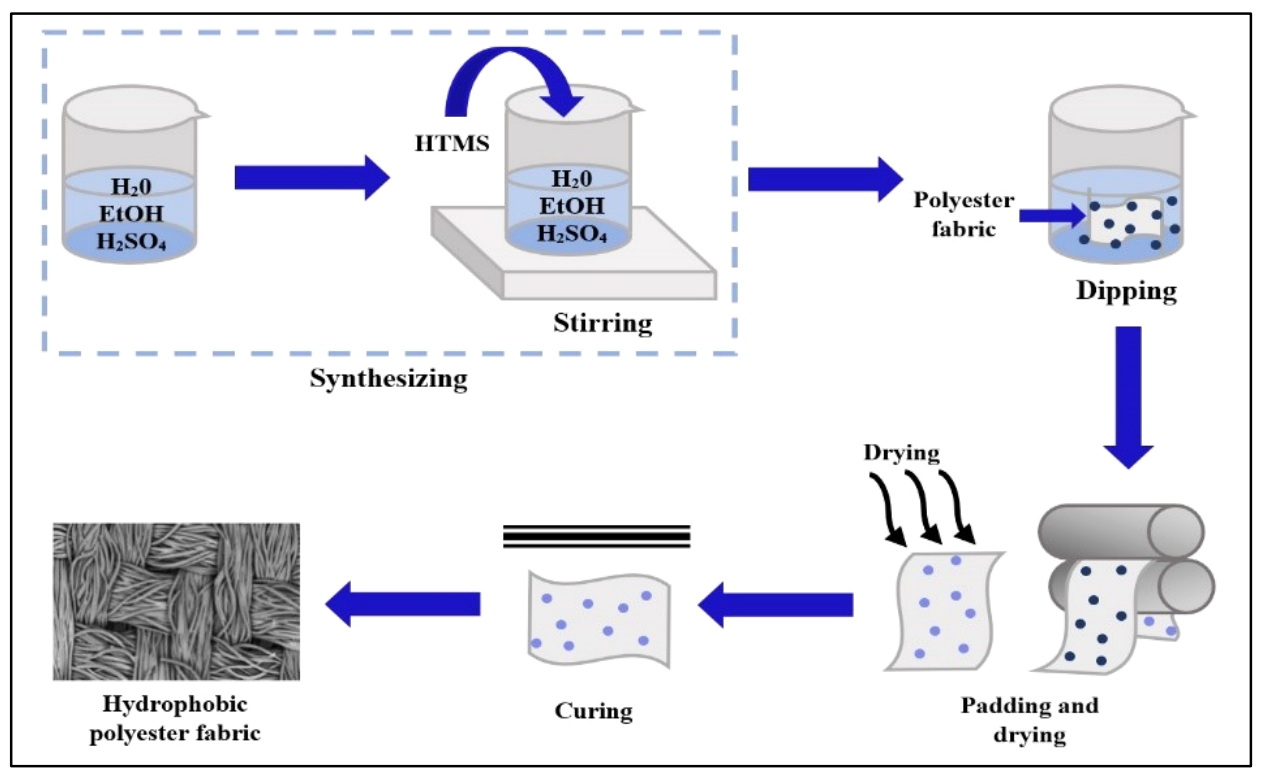

Figure 1. Synthesizing process of HTMS sols and treatment of polyester fabric. 


\section{2-3-Observation and Characterization}

The hydrophobicity effectiveness of the coated polyester fabric was first observed with naked eye. For this purpose, a few drops of water were scattered on five different surfaces of treated polyester fabrics $(1: 3,1: 12 ; 1: 20 ; 1: 30,1: 40)$ and left for 30 minutes. The best hydrophobic HTMS sol-gel coating was then selected for further characterization. The obtained coating solution was characterized for functional groups using Nicolet Is50 Fourier-transform infrared spectroscopy (FTIR) from Thermo Fischer Scientific. An attenuated total multiple reflection technique (ATR) was used to analyse the raw HTMS and 1:3 molar ratio HTMS sol-gel coating at range of $4000 \mathrm{~cm}^{-1}$ to $450 \mathrm{~cm}^{-1}$. The particle size was measured by Malvern Zetasizer Nano S90 laser diffraction particle size analyzer (PSA). The surface morphology and the elemental composition of the coated polyester sample were evaluated using scanning electron microscope with energy dispersive $\mathrm{x}$-ray detector (SEM-EDX) (Hitachi TM3030 Plus, operating at $10 \mathrm{keV}$ ). The water-silane effect was characterized by water contact angle (WCA) measured by OCA40 contact angle system (Dataphysics, Germany) using a $5 \mu \mathrm{l}$ water droplet at ambient temperature.

\section{3- Results and Discussion}

\section{3-1-Variation of Water Content}

Different ratios of $\mathrm{HTMS} / \mathrm{H}_{2} \mathrm{O}(1: 40,1: 30,1: 20,1: 12$ and 1:3) were prepared. Based on the observation, the time needed to obtain clear solution was 5 hours for the composition with a ratio 1:40 and the longest was 24 hours for the composition 1:3. The observed time to complete the reaction increased with the decrease in mol ratio of water. This effect was consistent with the findings by Azolin et al. [18] who concluded that a faster hydrolysis reaction occurred by the increase in the amount of water. The slow hydrolysis reaction may increase hydrolysis amount and the number of sites hydrolyzed, enhancing the Si-O-Si network formation. Additionally, in high hydrolysis reaction, a particulate like silica structure produced due to the ring formation condensation and growth mechanism which improved the adhesion properties of the sols [19]. Sols with higher water content led to less adhesive coatings with crack formation, resulting in penetration of the water from the substrate [20-21]. The sol-gel solution of ratio 1:3 was chosen as the best molar composition as it shows highest water repellency based on the hydrophobicity test shown in Figure 2 using $3 \times 3 \mathrm{~cm}$ sized polyester fabric samples. Only Sample 5 (1:3) shows no water penetration after 30 minutes. Thus, the sol-gel solution of 1:3 HTMS: $\mathrm{H}_{2} \mathrm{O}$ molar ratio was chosen for further characterization.

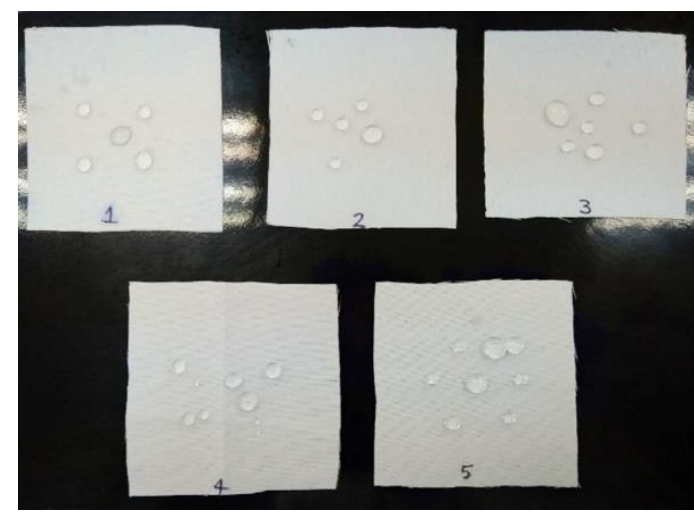

(a)

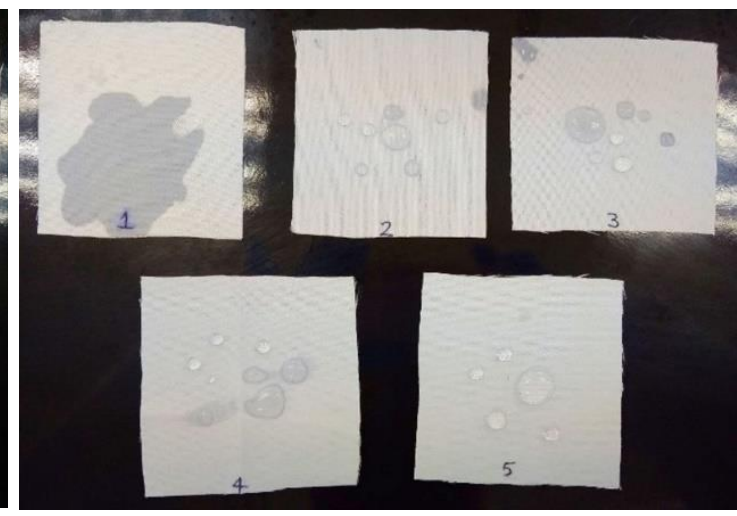

(b)

Figure 2. Polyester fabrics dipped with five different molar ratio of $\mathrm{HTMS}_{\mathrm{H}} \mathrm{H}_{2} \mathrm{O}$ coating solutions (1) 1:40, (2) 1:30, (3) 1:20, (4) 1:12 and (5) 1:3 after water dropping: (a) after a few seconds of water dropping; (b) after 30 minutes of water dropping.

\section{3-2- FTIR Analysis}

The first characterization of HTMS sol-gel coating was performed using FTIR. The spectra for raw HTMS and HTMS sol-gel coating with 1:3 molar composition was characterized using FTIR spectroscopy. Figure 3 shows the FTIR spectra for raw HTMS and HTMS sol-gel coating. They were recorded in the range between $4000 \mathrm{~cm}^{-1}$ to $450 \mathrm{~cm}^{-1} \mathrm{using}$ ATR technique as the samples were in liquid form. The characteristic absorption peaks at 2926 and $1458 \mathrm{~cm}^{-1}$ in raw HTMS and at $1409 \mathrm{~cm}^{-1}$ in the HTMS sol-gel coating helped to identify the $-\mathrm{CH}_{3}$ stretch vibration and the $\mathrm{C}-\mathrm{H}$ absorption [22]. Furthermore, sharp absorption peak at $803 \mathrm{~cm}^{-1}$ in the raw HTMS spectrum and broad peak at about $500 \mathrm{~cm}^{-1}$ in HTMS sol-gel coating indicated the Si-O vibration modes and $\mathrm{Si}-\mathrm{O}$ rocking respectively. The strongest band at $1081 \mathrm{~cm}^{-1}$ and medium band at $2839 \mathrm{~cm}^{-1}$ in the raw HTMS spectrum resulted from Si- $\mathrm{OCH}_{3}$ asymmetric stretching of silyl group. The broad peaks of $\mathrm{O}-\mathrm{H}$ bonds stretching at $3285 \mathrm{~cm}^{-1}$ which were attributed to uncondensed silanols and the characteristic absorption of Si-OH at $1643 \mathrm{~cm}^{-1}$ did not appear in the spectrum of the raw HTMS confirmed the hydrolysis of sol-gel process was successful. The characteristic absorption band of the condensation product of HTMS was also detected. The absorption bands at $1014 \mathrm{~cm}^{-1}$ were due to the symmetrical stretch vibrations that corresponded to the formation of three-dimensional Si-O-Si network in the HTMS sol-gel coating [23]. 


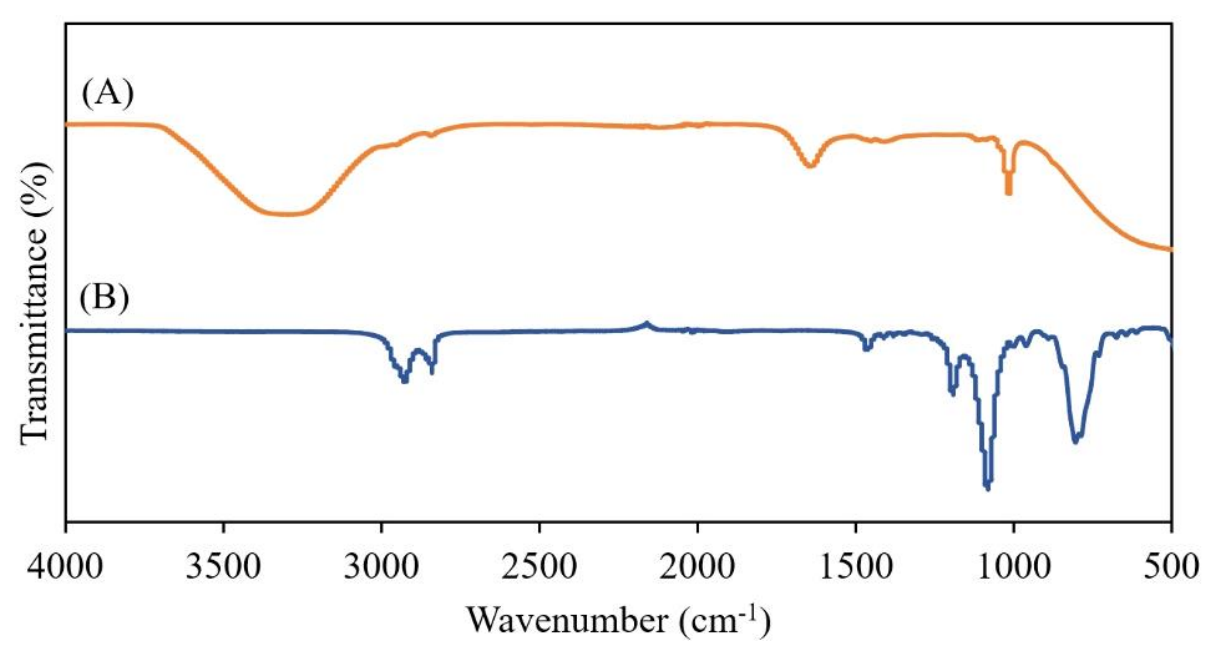

Figure 3. FTIR spectra of 1:3 molar composition of HTMS sol-gel coating (A) and raw HTMS (B).

\section{3-3- Particle Size Analysis.}

Size distribution of nanoparticles was reported to have a critical effect on enhancing various properties as it can alter the porosity of the coating [24]. Hence, the particle size of HTMS sol-gel coating was evaluated using particle size analyzer. The particle size of the HTMS sol-gel coating with 1:3 molar composition was measured at $115.3 \mu \mathrm{m}$. decreasing the water content to some extent causes the particle size to rise steeply. This was described by Kesmez et al. [25]. He concluded that the formation of larger particle size was due to the use of smaller water to precursor ratio and lower amount of acid catalyst. Additionally, at low water content, the silica nanoparticles initially form oligomers with small network size, aggregate and grow with each other to form a network structure with a high crosslinking degree [26]. According to Morita et al. [27] an increase of particle size, could decrease the total area of interaction between the fluids and solid surface. It results in lower energy required to remove a droplet, and thus, it increases the hydrophobicity of the surface. The decrease in the particle size was favourable in increasing trend of water content as it attributes to the hydrolytic depolymerisation reaction, which is the reverse reaction of condensation. Although the particle growth of $\mathrm{SiO}_{2}$ particle is complex, the control of the $\mathrm{SiO}_{2}$ particle size possible by altering the water/precursor ratio and acid catalyst/precursor ratio for a better coverage on the substrate.

\section{3-4- Water Contact Angle Measurement.}

In order to analyse the effect of 1:3 molar composition of sol-gel coating on hydrophobicity, static wettability study of WCA was conducted by using sessile drop method. A $5 \mu \mathrm{l}$ water droplet was tested on the fabric sample at ambient temperature and water contact angle of $136.2^{\circ}$ was obtained as shown in Figure 4. The $\mathrm{Si}-\mathrm{OH}$ groups on the $\mathrm{SiO}_{2}$ particles could react with the ester functional groups on polyester fiber surface resulting in the chemically linked of the HTMS: $\mathrm{H}_{2} \mathrm{O}$ sols with the polyester fabric. Silanes can alter the surface hydrophobicity due to the presence of alkyl chain which can shield the hydrophilic surface. The WCA increases in tandem with an increase of carbon atom number as the long alkyl chain has better ability to shield the substrate [28]. According to Kock-Yee [29], a surface is hydrophilic when its WCA is $<90^{\circ}$ and it is hydrophobic when it is $>90^{\circ}$. He obtained this finding from his in-depth study on the basis of the measured wetting and adhesion interactions between water and a variety of surfaces. Thus, the synthesized HTMS sol-gel coating was successful in creating a hydrophobic surface on the polyester fabric.

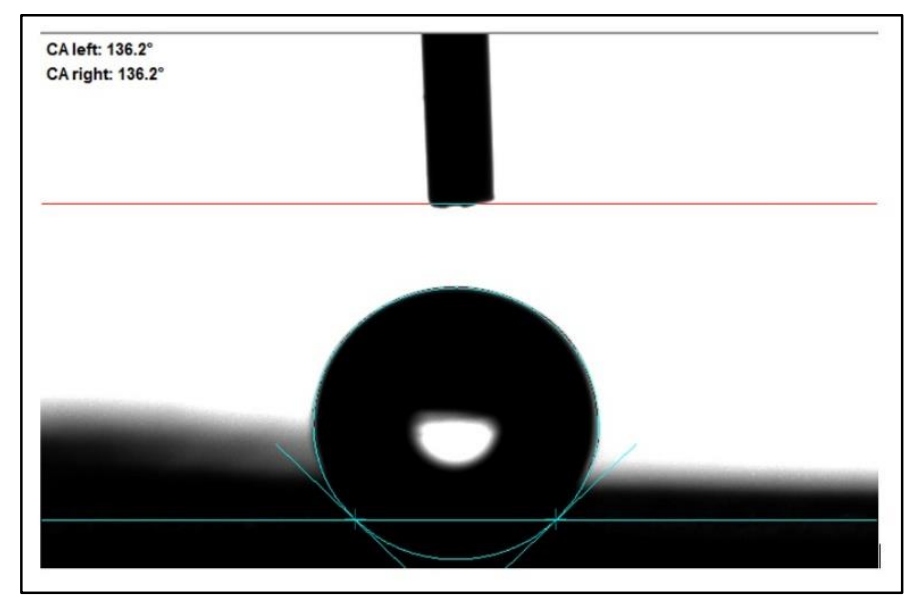

Figure 4. $5 \mu \mathrm{l}$ water droplet on coated polyester fabric. 


\section{3-5-SEM-EDX}

Surface morphology of the coated polyester fabric and elemental composition of the HTMS sol-gel coating were examined under SEM-EDX. The SEM-EDX images in Figure 5 show the ununiformed deposition of amorphous silica coating on the fabric fibre in the form of homogenous thin xerogel coating [30]. The formation of xerogel can be explained by the evaporation of solvents during the drying and curing process, whereby the capillary forces resulted in shrinkage and collapsed of the gel network. In addition, the reaction between alkoxysilanes and water was quite gentle avoiding phase separation and leading to good homogeneity [31]. From the images, it is clear this sol-gel formulation is able to produce a good HTMS sol-gel coating with the ability to coat the fibre without any cracks or fractures and managed to generate surface roughness indicating no undesirable agglomeration within the creation of the coatings. The formation of micro or nano bumps on the substrate can enhance the surface hydrophobicity which directly enhanced the WCA [32-33]. Additionally, the hydrophobicity of the substrate mainly depends on the surface roughness and surface energy [34].
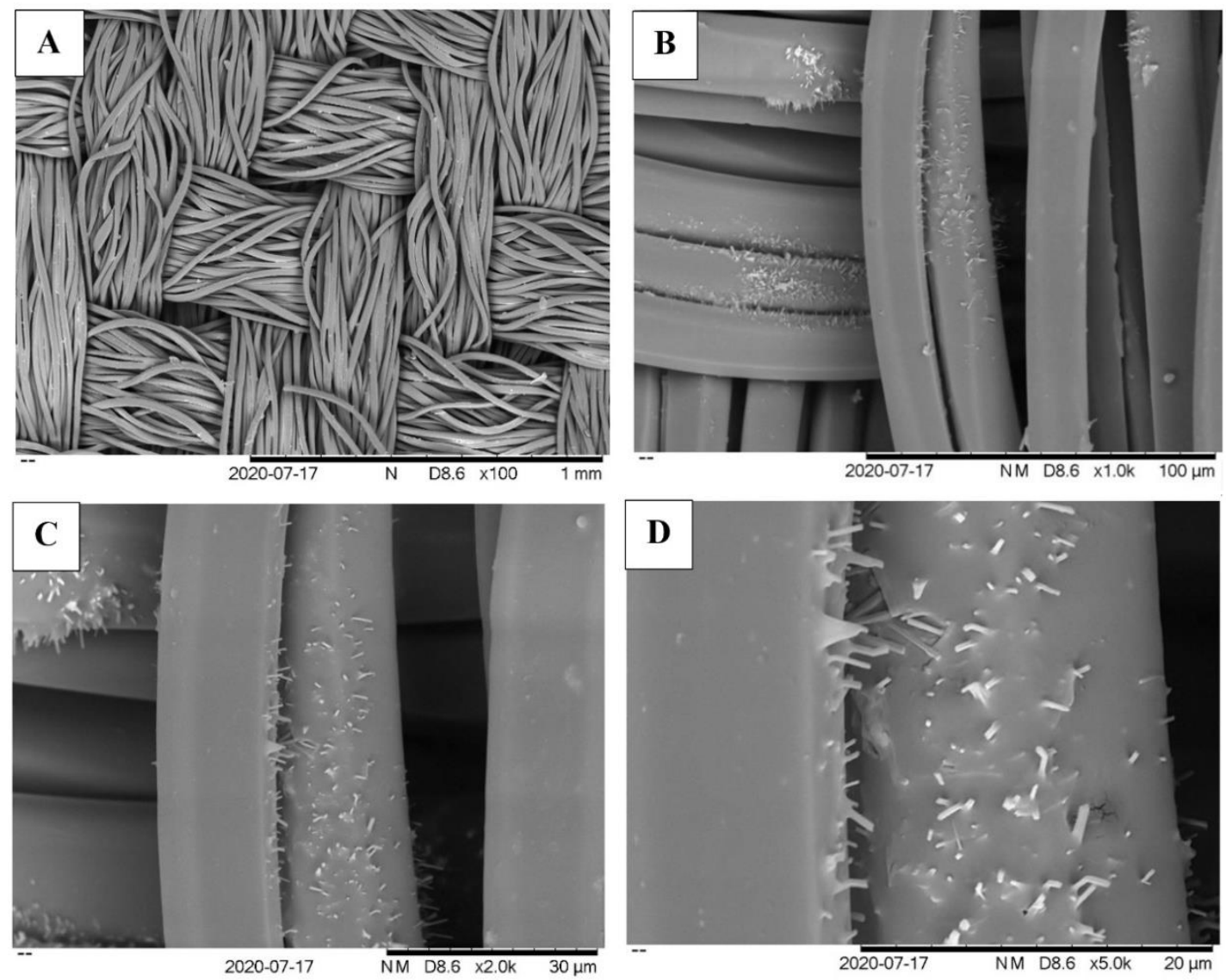

Figure 5. SEM images of coated polyester fabric surface at (A) 100, (B) 1 K, (C) 2 K, and (D) 5 K magnification.

The EDX analysis was applied to study the elemental composition of the treated polyester fabric. This technique was utilized to determine the presence of essential elements from the synthesized coating solution that need to be deposited on the fabric surface. Figure 6 shows the EDX spectrum with carbon, oxygen, silicon and aurum peaks. Carbon, silicon and oxygen come from the HTMS sol-gel materials while aurum was from gold sputtered-coating treated on the fabric sample before it was subjected to SEM analysis to improve conductivity. Deposit of the important elements of hydrophobic coating were verified as the peaks for carbon and silicon were high compared with the EDX spectrum of the untreated polyester fabric reported by El-Kheir et al. [35].

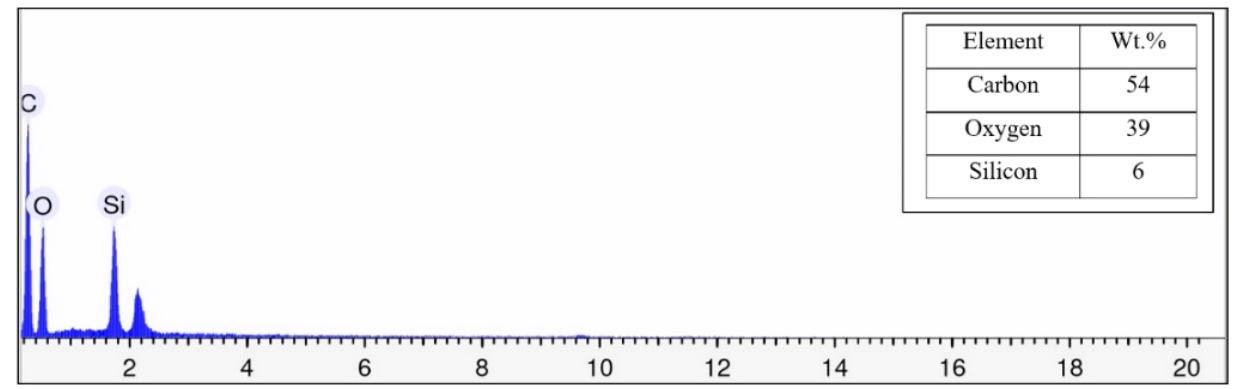

Figure 6. EDX spectrum of the coated polyester fabric surface. 


\section{4- Conclusion}

Water-repellent coating was successfully synthesized by utilizing HTMS as silica precursor using a water-based solgel system. This was performed under acid catalyst to produce gel-typed coating and a small amount of ethanol was introduced into the reaction to enhance the solubility and hydrolysis process. The molar ratio of HTMS to $\mathrm{H}_{2} \mathrm{O}$ was found to affect the interaction between the substance and its adhesion on the substrate. A molar ratio of 1:3 was selected as the best molar composition as it produces the highest hydrophobicity on the coated polyester fabric. The water contact angle obtained for 1:3 molar ratio HTMS: $\mathrm{H}_{2} \mathrm{O}$ coated on polyester fabric was $136.2^{\circ}$ by using sessile drop method. The particle size measured was $115.3 \mu \mathrm{m}$ which also attributed to the hydrophobicity effect of the coated polyester fabric. The presence of hydrolysis and condensation products in the sol-gel reaction were assured from the comparison of FTIR spectra of raw HTMS and the synthesized coating with the formation of Si-O-Si network. Moreover, the EDX analysis verified the coating deposition by the presence of silicon and carbon element on the coated polyester fabric. The SEM images showed good surface morphology of the homogenous thin xerogel coating with no visible cracks. Additionally, the sample managed to preserve their soft and smooth fabric nature and no hardening was observed after the coating treatment. This study has demonstrated that HTMS treated polyester fabric has a great potential as water repellent fabric and it is a promising candidate to meet the actual demand in the textile industry.

\section{5- Declarations}

\section{5-1-Author Contributions}

Conceptualization, W.N.W.I.; methodology, N.N.M.Z.; validation, W.N.W.I., and N.N.M.Z.; formal analysis, W.N.W.I., and N.N.M.Z.; investigation, N.N.M.Z.; resources, W.N.W.I.; data curation, N.N.M.Z.; writing—original draft preparation, N.N.M.Z.; writing-review and editing, W.N.W.I., and H.M.Y.; supervision, W.N.W.I.; project administration, W.N.W.I.; funding acquisition, W.N.W.I. All authors have read and agreed to the published version of the manuscript.

\section{5-2-Data Availability Statement}

The data presented in this study are available in article.

\section{5-3-Funding}

This research was funded by Universiti Malaysia Pahang (UMP) under Fundamental Research Grant RDU1903109.

\section{5-4-Acknowledgements}

The authors would like to express their gratitude to Universiti Malaysia Pahang for providing the research facilities that allowed this study to be carried out.

\section{5-5- Conflicts of Interest}

The authors declare that there is no conflict of interests regarding the publication of this manuscript. In addition, the ethical issues, including plagiarism, informed consent, misconduct, data fabrication and/or falsification, double publication and/or submission, and redundancies have been completely observed by the authors.

\section{6- References}

[1] Xu, L., W. Zhuang, B. Xu, and Z. Cai. "Superhydrophobic cotton fabrics prepared by one-step water-based sol-gel coating.” The Journal of the Textile Institute 103, no. 3 (October 2011): 311-319. doi:10.1080/00405000.2011.569238.

[2] Darmanin, T., and F. Guittard. "Superhydrophobic and superoleophobic properties in nature." Materials Today 18, no. 5 (June 2015): 273-285. doi:10.1016/j.mattod.2015.01.001.

[3] Kim, W., D. Kim, S. Park, D. Lee, H. Hyun, and J. Kim. "Engineering lotus leaf-inspired micro- and nanostructures for the manipulation of functional engineering platforms." Journal of Industrial and Engineering Chemistry 61 (May 2018): 39-52. doi:10.1016/j.jiec.2017.11.045.

[4] Simpson, J.T., S. R. Hunter, and T. Aytug. "Superhydrophobic materials and coatings: a review." Reports on Progress in Physics 78, no. 8 (July 2015): 086501. doi:10.1088/0034-4885/78/8/086501.

[5] Koohestani, B., A. K. Darban, E. Yilmaz, P. Mokhtari, and I. Ganetri. "Influence of amine and vinyl functional groups of silanes on total performance of thermoplastic-based composites." Construction and Building Materials 172 (May 2018): 98-105. doi:10.1016/j.conbuildmat.2018.03.235.

[6] Konstantin Volkov. "Heat Transfer - Models, Methods and Applications.” (June 27, 2018). doi:10.5772/intechopen.71737. 
[7] David Levy and Marcos Zayat. “The Sol-Gel Handbook.” (August 21, 2015). doi:10.1002/9783527670819.ch39.

[8] Danks, A. E., S. R. Hall, and Z. Schnepp. “The evolution of 'sol-gel' chemistry as a technique for materials synthesis.” Material Horizon 3, no. 2 (December 2016): 91-112. doi:10.1039/C5MH00260E.

[9] Ismail, W. N. W. "Sol-gel technology for innovative fabric finishing - A review.” Journal of Sol-gel Science and Technology 78 (March 2016): 698-707. doi:10.1007/s10971-016-4027-y

[10] Mohd Yusop, H., A.I.H. Mohd Ismail, and W.I. Wan Ismail. "Preparation and Characterization of New Sol-Gel Hybrid InulinTEOSAdsorbent.” Polymers 13 (April 2021): 1295. doi:10.3390/polym13081295

[11] Gong, X., and S. He. "Highly durable superhydrophobic polydimethylsiloxane/silica nanocomposite surface with good selfcleaning ability.” ACS Omega 5, no. 8 (February 2020): 4100-4108. doi:10.1021/acsomega.9b03775.

[12] Nabipour. H., X. Wang, L. Song, and Y. Hu. "Hydrophobic and flame-retardant finishing of cotton fabrics for water-oil separation.” Cellulose 27 (February 2020):4145-4159. doi:10.1007/s10570-020-03057-1

[13] Xu, L., W. Zhuang, B. Xu, and Z. Cai. "Fabrication of superhydrophobic cotton fabrics by silica hydrosol and hydrophobization." Applied Surface Science 257, no. 13 (April 2011): 5491-5498. doi:10.1016/j.apsusc.2010.12.116

[14] Kamiya, H., and M. Iijima. "Surface modification and characterization for dispersion stability of inorganic nanometer-scaled particles in liquid media." Science and Technology of Advanced Materials 1, no. 4 (September 2010): 044304. doi:10.1088/1468-6996/11/4/044304.

[15] Milea, C. A., C. Bogatu, and A. Duta. "The influence of parameters in sol-gel process." Bulletin of the Transilvania University of Braşov, Series I: Engineering Sciences 4, no. 1 (2011): 59-66.

[16] Espanhol-Soares, M., L. Costa, M.R.A. Silva, F.S. Silva, L.M.S. Ribeiro, and R. Gimenes. "Super-hydrophobic coatings on cotton fabrics using sol-gel technique by spray." Journal of Sol-Gel Science and Technology 95 (May 2020): 22-33. doi:10.1007/s10971-020-05307-x.

[17] Shevrin, J.D., S.D. Bergman, and Evonic. "Crosslinking waterborne Coatings with bipodal silanes for improved corossion protection performance.” CoatingsTech 16, no. 4 (April 2019).

[18] Azolin, D. R., C. C. Moro, T. M. H. Costa, and E. V. Benvenutti. "Effects of organic content and H2O/TEOS molar ratio on the porosity and pore size distribution of hybrid naphthaleneaminepropylsilica xerogel.” Journal of Non-Crystalline Solids 337, no 3 (July 2004): 201-206. doi:10.1016/j.jnoncrysol.2004.04.011.

[19] Najafabadi, H.A., R. Mozaffarinia, H. Rahimi, S.R. Razavi, and E. Paimozd. "Sol-gel processing of hybrid nanocomposite protective coatings using experimental design." Progress in Organic Coatings 76, no. 1 (January 2013): 293301. doi:10.1016/j.porgcoat.2012.09.027.

[20] Kelmansky, R., B.J. McAlvin, A. Nyska, J.C. Dohlman, H.H. Chiang, M. Hashimoto, D.S. Kohane, and B. Mizrahi. "Strong tissue glue with tunable elasticity." Acta Biomaterialia 53 (April 2017): 93-99. doi:org/10.1016/j.actbio.2017.02.009

[21] Mahltig, B. "Hydrophobic Silica Sol Coatings on Textiles - the Influence of Solvent and Sol Concentration." Journal of Sol-Gel Science and Technology 34 (November 2004):103-109.

[22] Xu, L., L. Wang, Y. Shen, Y. Ding, and Z. Cai. "Preparation of hexadecyltrimethoxysilane-modified silica nanocomposite hydrosol and superhydrophobic cotton coating." Fibers and Polymers 16 (June 2015): 1082-1091. doi:10.1007/s12221-0151082-x.

[23] Launer Philip, and Barry Arkles. "Silicon Compounds: Silanes and Silicones, Second Edition” (January 1, 2008).

[24] Bera, S., G. Udayabhanu, R. Narayan, and T. K. Rout. "Sol-gel process for anti-corrosion coatings.” Journal of Research Updates in Polymer Science 2, no. 4 (January 2013): 209-231. doi:10.6000/1929-5995.2013.02.04.4.

[25] Kesmez, Ö., E. Burunkaya, N. Kiraz, H. E. Çamurlu, M. Asiltürk, and E. Arpaç. "Effect of acid, water and alcohol ratios on solgel preparation of antireflective amorphous SiO2 coatings." Journal of Non-Crystalline Solids 357, no. 16-17 (August 2011): 3130-3135. doi:10.1016/j.jnoncrysol.2011.05.003.

[26] Zhao, X., Y. Wang, J. Luo, P. Wang, P. Xiao,and B. Jiang. “The Influence of Water Content on the Growth of the Hybrid-Silica Particles by Sol-Gel Method.” Silicon 58 (October 2020): doi:10.1007/s12633-020-00756-z.

[27] Morita, K., J. Gonzales, and H. Sakaue. "Effect of PTFE Particle Size on Superhydrophobic Coating for Supercooled Water Prevention." Coatings 8 (September 2018): 426. doi:10.3390/coatings8120426.

[28] Roe, B., R. Kotek, and X. Zhang. "Durable hydrophobic cotton surfaces prepared using silica nanoparticles and multifunctional silanes.” Journal of the Textile Institute 103, no. 4 (May 2011): 385-393. doi:10.1080/00405000.2011.580540.

[29] Kock-Yee, L. "Definitions for hydrophilicity, hydrophobicity, and superhydrophobicity: getting the basics right." Journal of Physical Chemistry Letters 5, no. 4 (February 2014): 686-688. doi:10.1021/jz402762h. 
[30] Brzeziński, S., D. Kowalczyk, B. Borak, M. Jasiorski, and A. Tracz. "Nanocoat finishing of polyester/cotton fabrics by the solgel method to improve their wear resistance." Fibres and Textile in Eastern Europe 19, no. 6 (November 2011): 83-88.

[31] Milea, C.A., C. Bogatu, and A. Duta. "The influence of parameters in sol-gel process." Bulletin of the Transilvania University of Braşov, Series I: Engineering Sciences 4, no. 1 (2011): 59-66.

[32] Zhu, X., Z. Zhang, J. Yang, X. Xu, X. Men, and X. Zhou. "Facile fabrication of a superhydrophobic fabric with mechanical stability and easy-repairability." Journal of Colloid Interface Science 380 (August 2012): 182-186. doi:10.1016/j. jcis.2012.04.063

[33] Anjum, A.S., M. Ali, K.C. Sun, R. Riaz, S.H. Jeong. "Self-assembled nanomanipulation of silica nanoparticles enable mechanochemically robust super hydrophobic and oleophilic textile.” Journal of Colloid and Interface Science 563 (December 2019): 62-73. doi:10.1016/j.jcis.2019.12.056

[34] Song, M., J. Ju, S. Luo, Y. Han, Z. Dong, Y. Wang, Z. Gu, L. Zhang, R. Hao, and L. Jiang. "Controlling liquid splash on superhydrophobic surfaces by a vesicle surfactant." Science Advances 3, no. 3 (March 2017): e1602188. doi:10.1126/sciadv.1602188.

[35] El-Kheir, A. A., N. A. A. El-Ghany, M. M. Fahmy, A. Sara, and L. K. El-Gabry. "Functional finishing of polyester fabric using bentonite nano-particles." Egyptian Journal of Chemistry 63, no. 1 (January 2020): 85-99. doi:10.21608/EJCHEM.2019.20404.2223. 